\title{
Three-Dimensional Printable Hydrogel Using a Hyaluronic Acid/Sodium Alginate Bio-Ink
}

\author{
Su Jeong Lee ${ }^{1,+}\left(\mathbb{D}\right.$, Ji Min Seok ${ }^{2,+} \oplus$, Jun Hee Lee ${ }^{2}$, Jaejong Lee ${ }^{3}$, Wan Doo Kim ${ }^{2, *}$ and Su A Park ${ }^{2, *}(\mathbb{D}$ \\ 1 Medical Device Convergence Center, Konyang University Hospital, Daejeon 35365, Korea; \\ sujeong@kyuh.ac.kr \\ 2 Department of Nature-Inspired System and Application, Korea Institute of Machinery and Materials (KIMM), \\ Daejeon 34103, Korea; jimins@kimm.re.kr (J.M.S.); meek@kimm.re.kr (J.H.L.) \\ 3 Department of Nano Manufacturing Technology, Korea Institute of Machinery \& Materials (KIMM), \\ Daejeon 34103, Korea; jilee@kimm.re.kr \\ * Correspondence: wdkim@kimm.re.kr (W.D.K.); psa@kimm.re.kr (S.A.P.) \\ + These authors contributed equally to this work.
}

Citation: Lee, S.J.; Seok, J.M.; Lee, J.H.; Lee, J.; Kim, W.D.; Park, S.A. Three-Dimensional Printable Hydrogel Using a Hyaluronic Acid/Sodium Alginate Bio-Ink. Polymers 2021, 13, 794. https:// doi.org/10.3390/polym13050794

Academic Editor: Chin-San Wu

Received: 15 February 2021

Accepted: 3 March 2021

Published: 5 March 2021

Publisher's Note: MDPI stays neutral with regard to jurisdictional claims in published maps and institutional affiliations.

Copyright: (c) 2021 by the authors. Licensee MDPI, Basel, Switzerland. This article is an open access article distributed under the terms and conditions of the Creative Commons Attribution (CC BY) license (https:// creativecommons.org/licenses/by/ $4.0 /)$

\begin{abstract}
Bio-ink properties have been extensively studied for use in the three-dimensional (3D) bio-printing process for tissue engineering applications. In this study, we developed a method to synthesize bio-ink using hyaluronic acid (HA) and sodium alginate (SA) without employing the chemical crosslinking agents of HA to $30 \%(w / v)$. Furthermore, we evaluated the properties of the obtained bio-inks to gauge their suitability in bio-printing, primarily focusing on their viscosity, printability, and shrinkage properties. Furthermore, the bio-ink encapsulating the cells (NIH3T3 fibroblast cell line) was characterized using a live/dead assay and WST-1 to assess the biocompatibility. It was inferred from the results that the blended hydrogel was successfully printed for all groups with viscosities of $883 \mathrm{~Pa} \cdot \mathrm{s}(\mathrm{HA}, 0 \% \mathrm{w} / v), 1211 \mathrm{~Pa} \cdot \mathrm{s}(\mathrm{HA}, 10 \% \mathrm{w} / v)$ ), and $1525 \mathrm{~Pa} \cdot \mathrm{s}$, (HA, $30 \% w / v)$ at a $0.1 \mathrm{~s}^{-1}$ shear rate. Their structures exhibited no significant shrinkage after $\mathrm{CaCl}_{2}$ crosslinking and maintained their integrity during the culture periods. The relative proliferation rate of the encapsulated cells in the HA/SA blended bio-ink was 70\% higher than the SA-only bio-ink after the fourth day. These results suggest that the 3D printable HA/SA hydrogel could be used as the bio-ink for tissue engineering applications.
\end{abstract}

Keywords: 3D bio-printing; bio-ink; biomaterial; sodium alginate; hyaluronic acid

\section{Introduction}

Three-dimensional (3D) printing techniques have been usually applied in the field of tissue engineering to fabricate a predesigned scaffold, regenerating a defected tissue in brief time [1,2]. In particular, 3D bio-printing systems can fabricate a construct using a hydrogel containing the live cells, i.e., bio-ink, without the cell seeding process for regenerating the defective sites in the body [3]. The hydrogel has been extensively studied in tissue engineering fields because of its potential to provide a suitable environment for the cells in the bio-ink, owing to its high water content, good biocompatibility, and controllable mechanical properties and biodegradability [4]. As one of the requirements of the bioprinting process, regulating the properties of the bio-ink is essential. This can be achieved by varying the types of the base materials composing the bio-ink to obtain the desired biological and physiological properties in various tissues [5]. As a natural polysaccharide, sodium alginate (SA) has been widely used as the base material in bio-printing, owing to its biocompatibility, biodegradability, and viscoelasticity to facilitate cell transplantation by printing [6]. However, SA cannot interact with mammalian cells, owing to its lack of cell adhesion moieties, which is an important requirement for cellular functions [7]. Therefore, studies have proposed that designing the bio-ink by blending various materials can potentially promote cellular activity in bio-inks comprising SA [8-10]. Recently, novel 
tools employing hyaluronic acid (HA) with SA to provide an improved environment to cells were extensively investigated for medical applications [11-13]. HA, a glycosaminoglycan that acts as a signaling molecule for cell migration and proliferation, has been extensively used as a hydrogel material in biomedical applications [14,15]. However, it is hard to design a controllable structure with the desired shape, porosity, and interconnected pores in the scaffold for the regeneration of large defects using conventional fabrication methods $[16,17]$. Therefore, a method for fabricating the scaffold using blended hydrogel and 3D bio-printing needs to be investigated.

In this study, we investigated a biologically enhanced bio-ink using HA, which could improve the cellular functionality of the bio-ink using the alginate alone for 3D bio-printing. We anticipate that SA can support the printability of the bio-ink, while HA enhances the bioactivity in the encapsulated cells. The mechanical properties, such as viscosity, printability, and biocompatibility of the 3D bio-printed scaffolds based on the prepared HA/SA blended bio-ink were analyzed.

\section{Materials and Methods}

\subsection{Preparation of the HA/SA Bio-Ink}

SA was purchased from Sigma-Aldrich (A2033, MO, USA). HA of $2500 \mathrm{kDa}$ was supplied from Humedix.Co. (Anyang, Korea). HA and alginate were dissolved in high glucose-DMEM (Dulbecco's Modified Eagle's Medium, Gibco, MD, USA) with 1\% penicillin/streptomycin and physically mixed in different ratio $(w / v)$ in a final concentration of $0 \%, 10 \%$ and $30 \%(w / v)$, respectively. The group names and compositions of the hydrogels are shown in Table 1. The hydrogels were prepared with three different HA/SA volume ratios. For making the bio-ink, the NIH3T3 cells were cultured in high glucose-DMEM supplemented with 10\% fetal bovine serum (Gibco, MD, USA) and 1\% penicillin/streptomycin (Gibco, MD, USA). These cultures were maintained in the incubator at $37{ }^{\circ} \mathrm{C}$ and $5 \%$ $\mathrm{CO}_{2}$. The cell encapsulated bio-ink gently mixed with HA/SA hydrogels to reach a final concentration of $1 \times 10^{6}$ cells $/ \mathrm{mL}$.

Table 1. Acronyms and compositions of the sodium alginate and hyaluronic acid blends.

\begin{tabular}{ccc}
\hline \multirow{2}{*}{ Acronym } & \multicolumn{2}{c}{ Composition $(\%, v / v)$} \\
\cline { 2 - 3 } & Sodium Alginate (S) & Hyaluronic Acid (H) \\
\hline S100H0 & 100 & 0 \\
S90H10 & 90 & 10 \\
S70H30 & 70 & 30 \\
\hline
\end{tabular}

\subsection{Fabrication and Characterization of the HA/SA Scaffold}

As shown in Figure 1, we used a 3D solid freeform fabrication (SFF) bio-printing system (laboratory made system in the Korea Institute of Machinery and Materials) [7]. We fabricated a cell-laden construct in a layer-by-layer fashion with the designed $20 \times 20 \times 1.5 \mathrm{~mm}^{3}$.

HA/SA hydrogels were analyzed by the rheometer (TA Instruments, New Castle, DE, USA) at the room temperature to measure the viscosities of the hydrogels. The infrared spectra of HA/SA hydrogel were measured using an FT-IR spectrophotometer (PerkinElmer, Waltham, MA, USA) measured spectrum condition at a resolution of $4.0 \mathrm{~cm}^{-1}$ over the range of 500-4000 $\mathrm{cm}^{-1}$. For the frequency sweep experiments, frequency was varied from 1 to $10 \mathrm{~Hz}$ at $5 \%$ strain while for the strain sweep experiments. The printability of the HA/SA hydrogels were evaluated by bio-printing system. To assess shrinkage behavior, the hydrogel printed structures were measured for size variation before and after treatment with $\mathrm{CaCl}_{2}$ (Sigma-Aldrich, St. Louis, MO, USA). The shrinking rate analysis of structure area was carried out using an image J program (NIH, Bethesda, MA, USA). 


\section{D bio-printing}

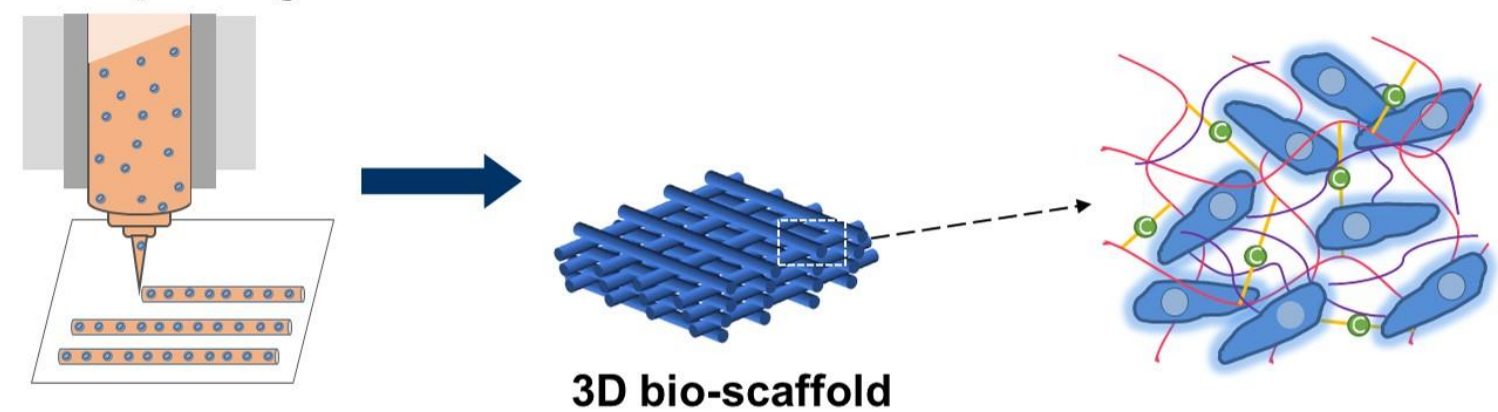

3D bio-scaffold

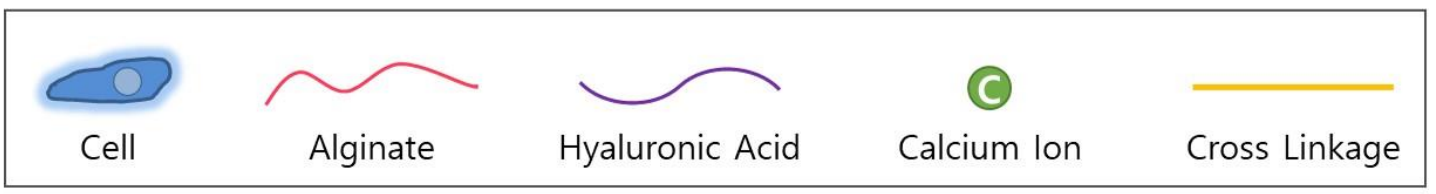

Figure 1. Schematic illustration of hyaluronic acid and alginate mixture as bio-ink for 3D bio-printing.

\subsection{Cytocompatibility of the Cultured Cells in HA/SA Scaffold}

For cell viability analysis, the encapsulated cells in the constructs were evaluated using a Live/Dead Cell assay kit (Molecular Probes, Invitrogen, Carlsbad, CA, USA) according to the manufacturer's instructions for 7 days. All the constructs were washed with PBS (phosphate buffered saline, Gibco, Gaithersburg, MD, USA), moved to another 24 well plate. The samples were stained for $20 \mathrm{~min}$ in the dark and washed 3 times in PBS. Live and dead cells were observed using fluorescence microscopy (Nikon, Tokyo, Japan). Furthermore, the cell-laden constructs were cut on $2.4 \times 2.4 \mathrm{~mm}^{2}$ size and then analyzed with WST-1 (Life Technologies, Carlsbad, CA, USA) to analyze the cell proliferation for 4 days. Briefly, the constructs were washed with PBS, moved to another 48 well plate. In the next, $40 \mu \mathrm{L}$ of WST-1 reagent and $400 \mu \mathrm{L}$ of serum free medium were added in each well and then incubated in the dark for $40 \mathrm{~min}$ at $37^{\circ} \mathrm{C}$. After incubation, $100 \mu \mathrm{L}$ of the incubated medium was transferred to a 96 well plate, and the absorbance at $450 \mathrm{~nm}$ was immediately measured using a microplate spectrophotometer (Bio-Rad, Hercules, CA, USA). The cell viability was examined after incubation for five samples per each group, and the WST-1 reagent with serum free medium was used as the blank control.

\subsection{Statistical Analysis}

All experiments were carried out at least three times and one-way analysis of variance was conducted for statistical analyses at the significance level of $p<0.05$.

\section{Results and Discussion}

\subsection{Fabrication and Characterization of the HA/SA Bio-Ink}

The SA is extensively used as the basement material of the bio-ink in the tissue engineering field because their physical and mechanical properties satisfy the requirements of an 'ideal' bio-ink [18]. As shown in Figure 2A, the viscosity of the blended bio-ink was visually increased with HA before pre-crosslinking. Moreover, these bio-inks after crosslinking were measured using rheometer to evaluate about their quantitative viscosity. $\mathrm{S} 100 \mathrm{H} 0, \mathrm{~S} 90 \mathrm{H} 10$, and S70H30 had viscosities of 883,1211 , and $1525 \mathrm{~Pa} \cdot \mathrm{s}$, respectively, at a $0.1 \mathrm{~s}-1$ shear rate (Figure 2B). In particular, all of the bio-inks were shown the shear thinning behavior decreasing shear viscosity with increasing shear rate. As the results, the viscosity of the bio-ink increased with HA, which satisfied with the condition to encapsulate the cells in the hydrogel and could be matched with the elasticity of the various soft tissue [19]. 


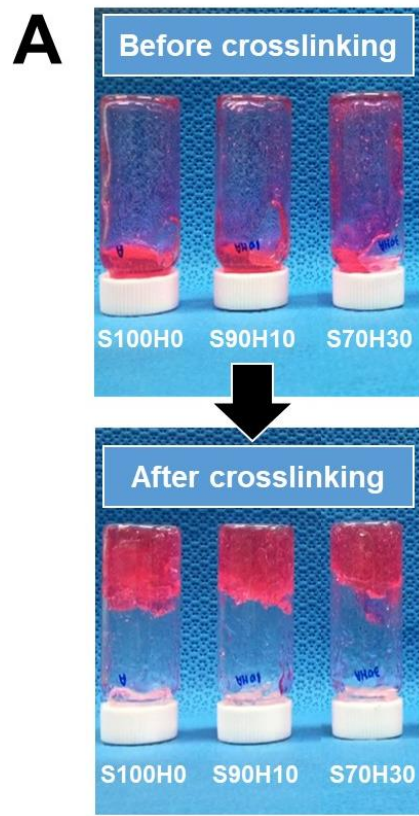

B

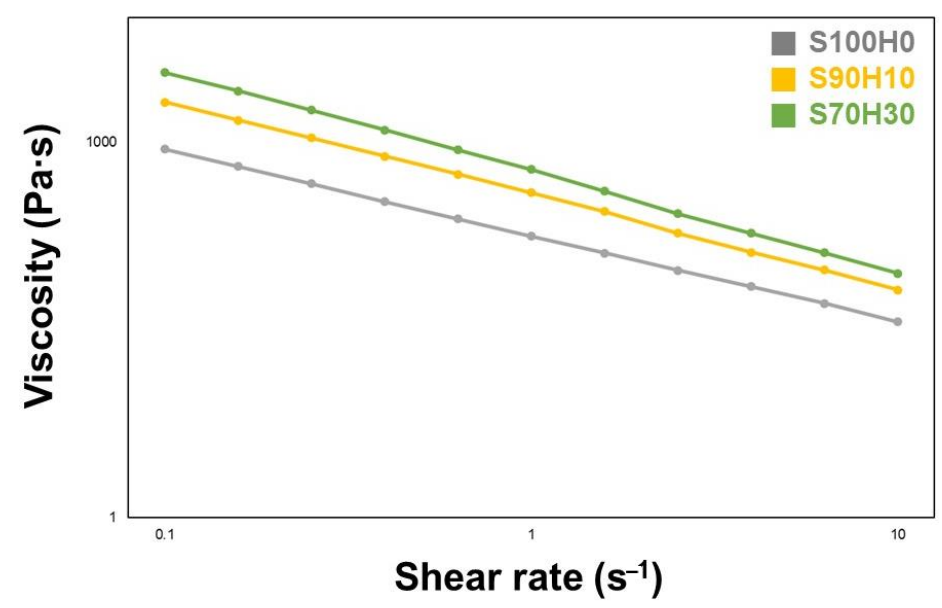

Figure 2. Viscosity of the bio-ink hyaluronic acid and alginate mixture as bio-ink for 3D bio-printing. (A) Blended bio-inks before pre-crosslinking (top) and after pre-crosslinking (bottom) with $1 \% \mathrm{CaCl}_{2}$ (B) Viscosity of the pre-crosslinked bio-inks.

To characterize the chemistry of the HA/SA blends, we analyzed the pre-crosslinked hydrogels by using FT-IR. As shown in Figure 3, the $-\mathrm{OH}$ stretching vibrations were observed at $3255.88 \mathrm{~cm}^{-1}$ in S100H0, which shifted with adding $\mathrm{HA}$ at $3246.46 \mathrm{~cm}^{-1}$ in $\mathrm{S} 70 \mathrm{H} 30$. The alkane $-\mathrm{CH}$ stretching vibrations were measured at $2883.43 \mathrm{~cm}^{-1}$ in $\mathrm{S} 100 \mathrm{HO}$, which also shifted with adding HA at $2927.59 \mathrm{~cm}^{-1}$ in S70H30. The asymmetric and symmetric stretching of the carboxyl group of SA at 1605.26 and $1404.79 \mathrm{~cm}^{-1}$ in S100H0 were shifted with adding HA at 1598.44 and $1408.80 \mathrm{~cm}^{-1}$ in S70H30, respectively [20,21]. These results were consistent with the analysis of the viscosity and bio-inks were successfully blended according to the ratio of HA/SA. Based on these results, we printed the bio-ink using 3D bio-printer.

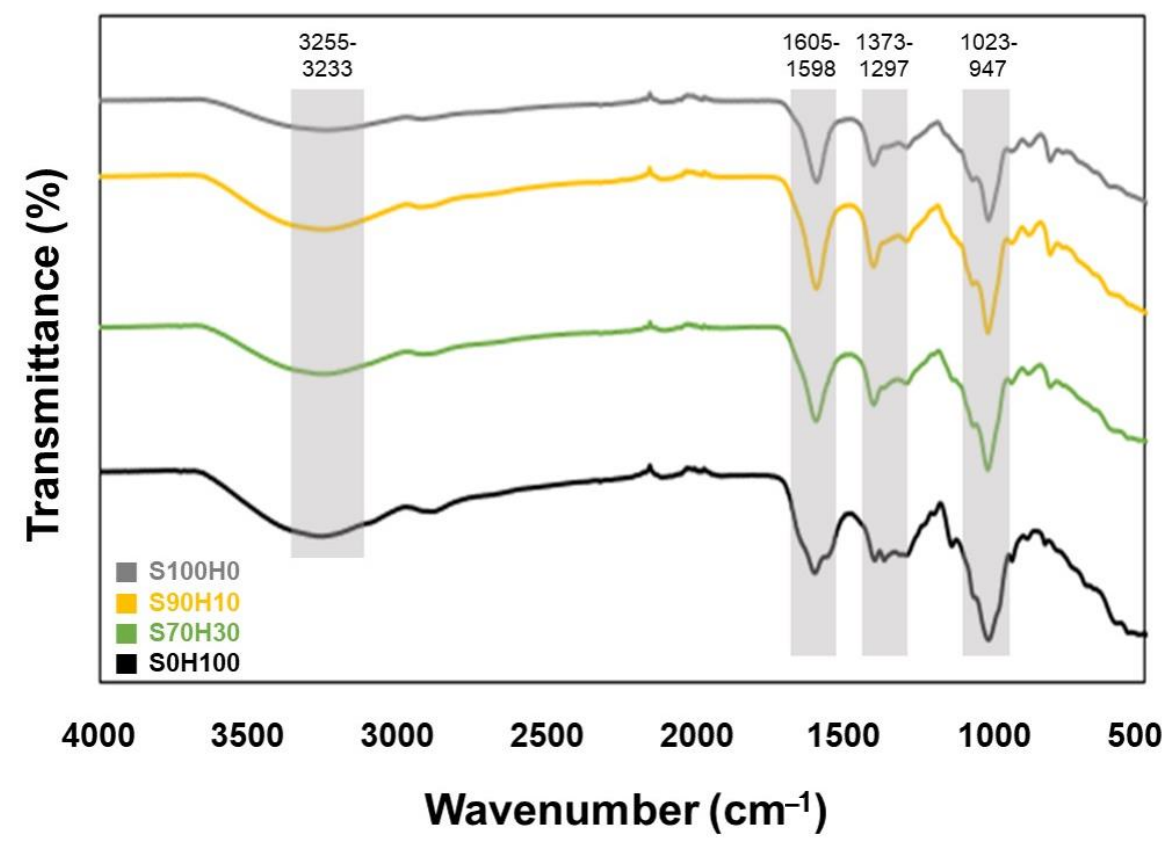

Figure 3. FT-IR spectrum of the bio-inks. 


\subsection{Fabrication and Characterization of the HA/SA Scaffold}

The scaffolds were printed after preparation and characterization of the bio-ink. In Figure 4, the all of bio-inks were completely plotted with maintained their structure from the nozzle at the printing head in the same printing conditions. In particular, the precrosslinked SA hydrogel with $1 \% \mathrm{CaCl}_{2}$ was used for appropriate printing, and then, the scaffolds successfully fabricated with stacked layer-by-layer without any crosslinking of the HA. Even though the size of the strands increased compared to SA-only bio-ink, the scaffolds maintained their porous structure after stacking process. These results indicated the pre-crosslinking rate dependent on the ratio of SA has an important role to construct the strut in the scaffold in contrast to the viscosity results. Furthermore, as shown in Figure 5, post-crosslinking process using with $5 \% \mathrm{CaCl}_{2}$ was carried out for fully cross-linked SA to stable structure, which could prevent collapse entire structure in early time. One of the major challenges for successful tissue regeneration, the scaffold must maintain the structure during application periods [22]. Although shrinkage rate decreased with the ratio of HA in the bio-ink, we anticipate that the structural stability of the scaffold could better with the ratio of SA.

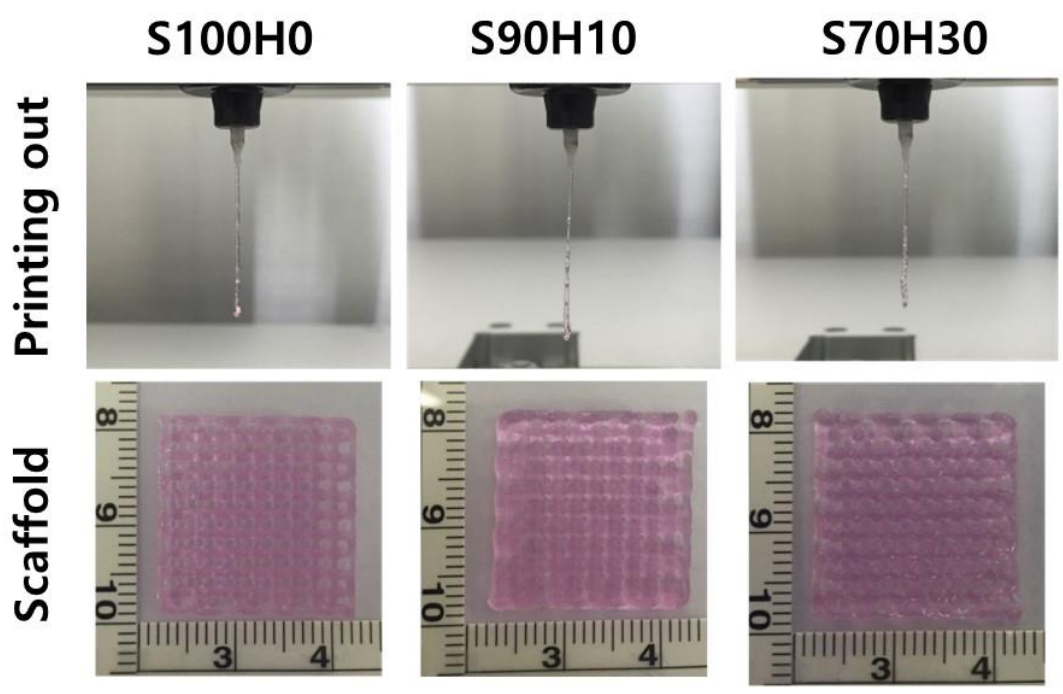

Figure 4. Printability of the bio-inks.

\section{$\mathrm{S} 100 \mathrm{HO}$}

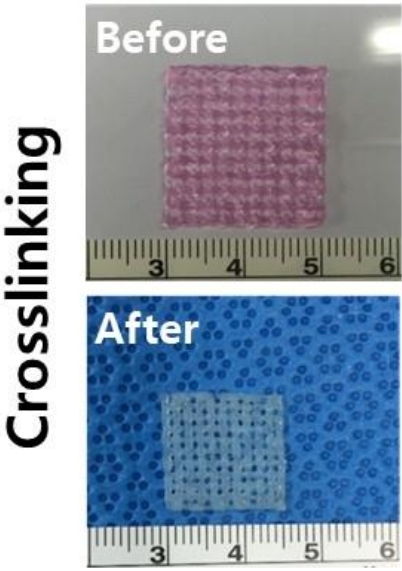

$\mathrm{S} 90 \mathrm{H} 10$
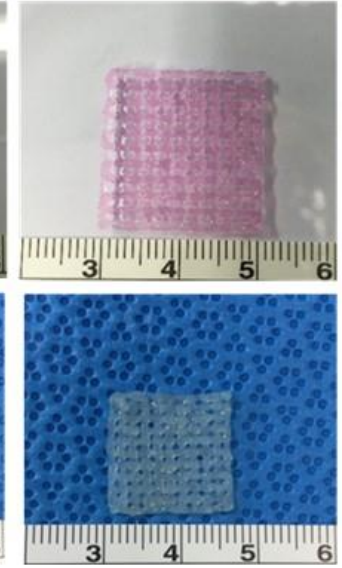

$\mathrm{S} 70 \mathrm{H} 30$
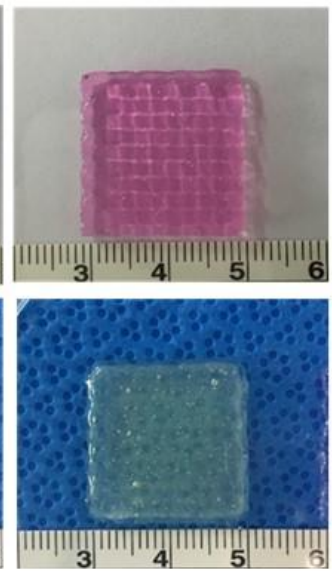

Figure 5. Structure of the scaffolds after crosslinking with $5 \% \mathrm{CaCl}_{2}$. 


\subsection{Cytocompatibility of the Cultured Cells in HA/SA Scaffold}

Cell viability and the cell proliferation of the scaffolds using Live/Dead staining and WST-1 assay, respectively. As shown in Figure 6, the scaffold maintains their structure in the $\mathrm{S} 100 \mathrm{H} 0$ and $\mathrm{S} 90 \mathrm{H} 10$ scaffold for 7 days although the degradation of the scaffold was shown in $\mathrm{S70H} 30$ scaffold at 7 day. This result means the structural stability by crosslinking rate of SA have a critical role in the bio-printed scaffold. However, the encapsulated cells were successfully live in the all groups, especially, the viability of the cells increased with the ratio of the HA in the bio-ink.

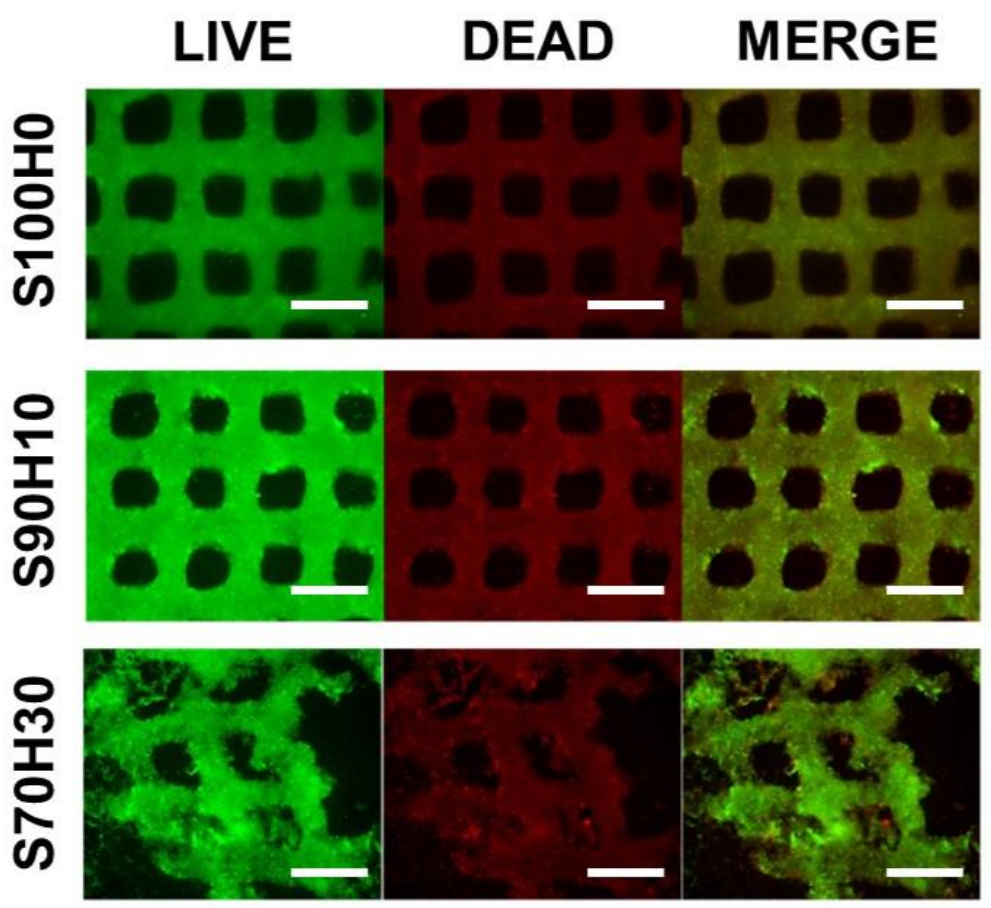

Figure 6. Cell viability of the encapsulated cells in the scaffolds. (scale bar $=1000 \mu \mathrm{m})$.

Furthermore, in Figure 7, the cell proliferation property of the scaffolds increased for 4 days. There was no significant difference between $\mathrm{S100H0}$ at day 1 and day 4 . However, the cell proliferation of the scaffolds increased until 4 days in the case of the $590 \mathrm{H} 10$ and $\mathrm{S} 70 \mathrm{H} 30$ scaffolds. These results mean HA could enhance the viability of the encapsulated cells with biological interactions of extracellular matrix [23]. In particular, one of important criterion to print the cell-laden bio-ink is that the bio-ink should come out of the nozzle with minimum applied shear force may damage the cells and reduce the cell viability in the printed constructs [24]. In this work, we suggest the blended HA could improve a protective function of bio-ink than SA-only. Therefore, the HA could positively effects on the cell viability and proliferation of the scaffold although it weakens the crosslinking of the scaffolds because of the HA ratio in the bio-ink that was not cross-linked. Based on the results, we anticipate the HA/SA blended hydrogel could be used as a bio-ink for enhancing cell activities by regulating the ratio of the HA in tissue engineering field and biomedical applications. 


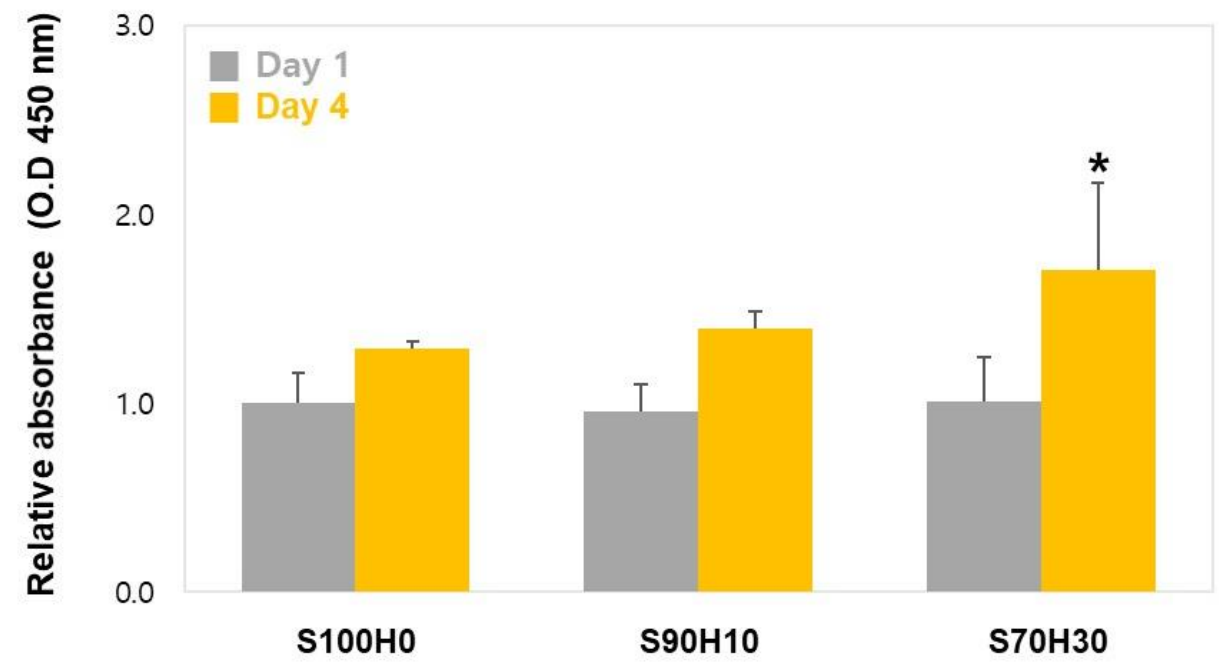

Figure 7. Proliferation of the encapsulated cells in the scaffolds. (Normalized at $\mathrm{S} 100 \mathrm{H} 0$, Day $1, \mathrm{n}=3$, ${ }^{*} p<0.05$, asterisks $\left(^{*}\right)$ was compared to $\mathrm{S} 100 \mathrm{H} 0$ ).

\section{Conclusions}

In this study, we developed the HA/SA blended hydrogel bio-ink for 3D bio-printing application. The viscosity of the bio-inks was regulated HA with pre-crosslinking treatment using $\mathrm{CaCl}_{2}$, which also well-blended physically according to the ratio of the hydrogels. In particular, the cell viability and proliferation increased with adding the ratio HA in the bio-ink although that were more disintegrated than SA-only scaffold. Furthermore, we could improve the bio-ink properties by applying the motif to enhance the binding affinity with cells on SA hydrogel and increasing the crosslinking property of HA to enhance the cell viability as well as the structural stability. Consequently, we suggest that these blended 3D printable HA/SA hydrogel potentially could be a good candidate for the application of the soft tissue regeneration.

Author Contributions: Conceptualization, S.J.L. and S.A.P.; methodology, S.J.L. and J.M.S.; validation, J.H.L.; investigation, S.A.P.; resources, W.D.K.; data curation, J.L.; writing-original draft preparation, S.J.L. and J.M.S.; writing — review and editing, S.A.P.; visualization, S.J.L.; supervision, S.A.P. and W.D.K.; project administration, J.H.L.; funding acquisition, S.A.P. and S.J.L. All authors have read and agreed to the published version of the manuscript.

Funding: This research was supported by the National Research Foundation (NRF) funded by the Korean government (MSIT; No. NRF-2019M3A9E2066348 and 2020M3H4A1A02084828 to Su A Park). This research was also supported by the Korean Health Technology R\&D Project grant through the Korea Health Industry Development Institute (KHIDI), funded by the Ministry of Health \& Welfare (HI17C2412 to Su Jeong Lee).

Institutional Review Board Statement: Not applicable.

Informed Consent Statement: Not applicable.

Data Availability Statement: The data presented in this study are available on request from the corresponding author.

Acknowledgments: This research was supported by the National Research Foundation (NRF) funded by the Korean government (MSIT; No. NRF-2019M3A9E2066348 and 2020M3H4A1A02084828) and a grant of the Korea Health Technology R\&D Project through the Korea Health Industry Development Institute (KHIDI), funded by the Ministry of Health \& Welfare, Republic of Korea (grant number: HI17C2412).

Conflicts of Interest: The authors declare no conflict of interest. 


\section{References}

1. Jammalamadaka, U.; Tappa, K. Recent advances in biomaterials for 3D printing and tissue engineering. J. Funct. Biomater. 2018, 9, 22. [CrossRef]

2. Ji, S.; Guvendiren, M. Recent advances in Bioink design for 3D bioprinting of tissues and organs. Front. Bioeng. Biotechnol. 2017, 5, 23. [CrossRef]

3. Jakus, A.E.; Rutz, A.L.; Shah, R.N. Advancing the field of 3D biomaterial printing. Biomed. Mater. 2016, 11, 014102. [CrossRef] [PubMed]

4. Heinrich, M.A.; Liu, W.; Jimenez, A.; Yang, J.; Akpek, A.; Liu, X.; Pi, Q.; Mu, X.; Hu, N.; Schiffelers, R.M.; et al. 3D Bioprinting: From benches to translational applications. Small 2019, 15, 1805510. [CrossRef]

5. Rastogi, P.; Kandasubramanian, B. Review of alginate-based hydrogel bioprinting for application in tissue engineering. Biofabrication 2019, 11, 042001. [CrossRef]

6. Jia, J.; Richards, D.J.; Pollard, S.; Tan, Y.; Rodriguez, J.; Visconti, R.P.; Trusk, T.C.; Yost, M.J.; Yao, H.; Markwald, R.R.; et al. Engineering alginate as Bioink for bioprinting. Acta Biomater. 2014, 10, 4323-4331. [CrossRef]

7. Park, J.; Lee, S.J.; Chung, S.; Lee, J.H.; Kim, W.D.; Lee, J.Y.; Park, S.A. Cell-laden 3D bioprinting hydrogel matrix depending on different compositions for soft tissue engineering: Characterization and evaluation. Mater. Sci. Eng. C 2017, 71, 678-684. [CrossRef]

8. Wei, L.; Li, Z.; Li, J.; Zhang, Y.; Yao, B.; Liu, Y.; Song, W.; Fu, X.; Wu, X.; Huang, S. An approach for mechanical property optimization of cell-laden alginate-gelatin composite Bioink with bioactive glass nanoparticles. J. Mater. Sci. Mater. Med. 2020, 31, 103. [CrossRef] [PubMed]

9. Ahmad Raus, R.; Wan Nawawi, W.M.F.; Nasaruddin, R.R. Alginate and alginate composites for biomedical applications. Asian J. Pharm. Sci. 2021. [CrossRef]

10. Antich, C.; de Vicente, J.; Jiménez, G.; Chocarro, C.; Carrillo, E.; Montañez, E.; Gálvez-Martín, P.; Marchal, J.A. Bio-inspired hydrogel composed of hyaluronic acid and alginate as a potential Bioink for 3D bioprinting of articular cartilage engineering constructs. Acta Biomater. 2020, 106, 114-123. [CrossRef] [PubMed]

11. Baldino, L.; Cardea, S.; Scognamiglio, M.; Reverchon, E. A new tool to produce alginate-based aerogels for medical applications, by supercritical gel drying. J. Supercrit. Fluids 2019, 146, 152-158. [CrossRef]

12. Liu, Z.; Ran, Y.; Xi, J.; Wang, J. Polymeric hybrid aerogels and their biomedical applications. Soft Matter 2020, 16, 9160-9175. [CrossRef] [PubMed]

13. Palma, P.J.; Ramos, J.C.; Martins, J.B.; Diogenes, A.; Figueiredo, M.H.; Ferreira, P.; Viegas, C.; Santos, J.M. Histologic Evaluation of regenerative endodontic procedures with the use of chitosan scaffolds in immature dog teeth with apical periodontitis. J. Endod. 2017, 43, 1279-1287. [CrossRef] [PubMed]

14. Borzacchiello, A.; Russo, L.; Malle, B.M.; Schwach-Abdellaoui, K.; Ambrosio, L. Hyaluronic acid-based hydrogels for regenerative medicine applications. Biomed. Res. Int. 2015, 2015, 871218. [CrossRef]

15. Park, H.; Woo, E.K.; Lee, K.Y. Ionically cross-linkable hyaluronate-based hydrogels for injectable cell delivery. J. Control. Release 2014, 196, 146-153. [CrossRef]

16. Song, S.J.; Choi, J.; Park, Y.D.; Hong, S.; Lee, J.J.; Ahn, C.B.; Choi, H.; Sun, K. Sodium alginate hydrogel-based bioprinting using a novel multinozzle bioprinting system. Artif. Organs 2011, 35, 1132-1136. [CrossRef]

17. Puertas-Bartolomé, M.; Włodarczyk-Biegun, M.K.; Del Campo, A.; Vázquez-Lasa, B.; Román, J.S. 3D Printing of a reactive hydrogel bio-ink using a static mixing tool. Polymers 2020, 12, 1986. [CrossRef]

18. Chung, J.H.Y.; Naficy, S.; Yue, Z.; Kapsa, R.; Quigley, A.; Moulton, S.E.; Wallace, G.G. Bio-ink properties and printability for extrusion printing living cells. Biomater. Sci. 2013, 1, 763-773. [CrossRef]

19. Rutz, A.L.; Hyland, K.E.; Jakus, A.E.; Burghardt, W.R.; Shah, R.N. A multimaterial bioink method for 3D printing tunable, cell-compatible hydrogels. Adv. Mater. 2015, 27, 1607-1614. [CrossRef]

20. Wang, M. Preliminary Study on the Fabrication of Alginate/Hyaluronic Acid scaffolds for Spinal Cord Injury Repair. University of Saskatchewan, 2012. Available online: http:/ /hdl.handle.net/10388/ETD-2012--08--556 (accessed on 3 March 2021).

21. Chen, Y.-H.; Li, J.; Hao, Y.-B.; Qi, J.-X.; Dong, N.-G.; Wu, C.-L.; Wang, Q. Preparation and characterization of composite hydrogels based on crosslinked hyaluronic acid and sodium alginate. J. Appl. Polym. Sci. 2015, 132, 41898. [CrossRef]

22. Kyle, S.; Jessop, Z.M.; Al-Sabah, A.; Whitaker, I.S. "Printability" of candidate biomaterials for extrusion Based 3D printing: State-of-the-Art. Adv. Healthc. Mater. 2017, 6, 1700264. [CrossRef] [PubMed]

23. Noh, I.; Kim, N.; Tran, H.N.; Lee, J.; Lee, C. 3D printable hyaluronic acid-based hydrogel for its potential application as a bioink in tissue engineering. Biomater. Res. 2019, 23, 3. [CrossRef] [PubMed]

24. Murphy, S.V.; Atala, A. 3D bioprinting of tissues and organs. Nat. Biotechnol. 2014, 32, 773-785. [CrossRef] 